\title{
What Mathemagenic Activity Means: A Cognitive Pathway In Learning Chemistry
}

T. Orimogunje, Adekunle Ajasin University, Nigeria

\begin{abstract}
The purpose of this paper is to examine some mathemagenic activities that would transform the internal representations of learners' cognitive structure. The paper pointed out that understanding scientific concept involves the learner's role in translating instructive information into internal representation through the use of some mathemagenic activities. It also described how a student is being motivated toward some external stimuli in order to reorganize his/her thought in light of the teacher's feedback or action. This paper suggests that students would learn meaningfully, develop self-confidence, freely participate in classroom activities, and express himself/herself when allowed to use mathemagenic activities to clarify chemistry concepts that appear to be difficult to students. It is hoped that this study would enable educational planners and policymakers at local, state and national levels to redefine ways of improving the learning of scientific concepts through the use of mathemagenic activities in line with the policy of education. The implications of this study to the student and teacher are discussed.
\end{abstract}

Keywords: Mathemagenic Activity; Mathemagenic Activities and Cognitive Conception of Learning; Cognitive Pathway to Learning

\section{INTRODUCTION}

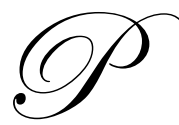

sychologists and educators have long been interested in understanding how people learn. Teaching, child rearing, counseling, and a wide variety of training situations are all concerned, in one way or the other, with individuals learning new knowledge or behaviors. Studies (Sa'adah and Siow, 2003) have shown that students enter science class with a set of pre-conceived ideas about scientific phenomena. Despite formal instruction in the chemistry class, students have been observed to exhibit scientific conceptions that were at variance with those that are generally accepted by the scientific community. It was reported by the chief examiner of WAEC and GCE (O/L) examinations in 2008 that candidates avoided questions which involved mathematical models arisen from quantitative chemistry. Some students show poor understanding of the demand of the questions by giving nontheoretical answers to practical questions, which has led to poor achievement, calling for attention. In the past, little attention was paid to the learner's role in translating instructive information into internal representation due to the mindset of instructional researchers rather than that of Zeitgeist behavior (Rothkopt, 1996). Behavioral psychologists have shed some light on the learning process and proposed mathemagenic activities as those that give birth to learning.

The task of teaching chemistry concepts meaningfully to students is sometimes complicated and is often not fulfilled because of the abstract nature of the subject. As chemistry continues to influence the world more and more, it is important that we learn to make chemistry sensible and accessible to many people by the use of appropriate strategies. One of the strategies that can achieve the purpose of helping students learn and study chemistry effectively is mathemagenic activity.

\section{Concept of Mathemagenic Activity}

Mathemagenic activity represents a model of the learner's action in an interactive process in a social setting. It is problem-solving oriented which allows students to explore and work individually, making meaningful learning tasks and setting out to solve problems that are perplexing to them (Laurillard, 1993). The study of 
mathemagenic activity is an area of instructional research which emerged in about the mid-60s. It started with Ausubel's 1963 study of meaningful verbal learning called sub-sumption theory. This theory elucidates the state and internal operations of a learners' memory in order to influence meaningful learning outcomes or responses. Mathemagenic activities are those that facilitate learning (Rothkopf, 1963; Laurillard, 1996; and Jonassen, 1988). Several empirical studies have been carried out in Europe and America to ascertain the effectiveness of these activities that enhance verbal learning (Frazer, 1970, and Ausubel, 1980). Besides, some studies have been carried out locally which corroborate the findings of Ausubel and his associates on the usefulness and influence of mathemagenic activities in the teaching-learning process (Ibegbulum, 1980; Nwankpa, 1981; Balogun, 1976; and Egbungara, 1983).

Orimogunje (2011) investigated the relative effect of some mathemagenic activities and the learning of some chemistry concepts among the secondary school students in Ondo State. The results of the study show that the experimental subjects, especially those groups with instructional objectives and adjunct questions, performed significantly better than the control group in cognitive tasks. From this study, it was observed that if the teacher can specify his/her lesson by using instructional objectives, it will enable the students to recall relevant facts and information in solving problems, especially those that involves volumetric analysis. The word 'mathemagenic' comes from the Greek words 'mathemain' (that which is learned) and 'gineisthos' (to give birth). The term mathemagenic activity was chosen to be some relevant activities that give birth to learning. That is, well prepared learning activities will break complex skills down into small steps so that students develop skills in manageable portions. This enables students to be actively involved in the learning process so as to check and gauge their progress from time to time.

Mathemagenic activities are both observable and unobservable student's actions that are relevant in achieving particular learning goals in specified situations (Ruthkopf, 1996, 2009). The first of these involves gross activities that bring the learner within physical reach of the instructive information. This is called overtmathemagenic or observable event. These activities include the use of advance organizers, post-organizers, adjunct questions in texts, instructional objectives in texts, and study habits. Also, linked to over-mathemagenic activities are eye movements, changes in skill resistance, and other physiological responses. The second class of activities is called covert-mathemagenic activities which are hypothetical mental processes that are characterized by their functions, such as selection, representation, collation, elaboration, and integration of information.

\section{Cognitive Conception of Mathemagenic Activity}

The cognitive orientation of learning is clearly evident in research topics such as meaningful verbal learning (Ausubel, 1980), Discovery teaching (Efimova, 2005), and mathemagenic activities (Rothkopf, 2009). These studies showed that learning was brought about as a result of stimulus and response. They believed that learning was the result of a continuous interaction between the learner and the world. Drapper (2000) argued that learners have preferences in the way in which they learn and that teachers should take cognizance of this phenomenon when designing learning materials. Drapper categorizes learning styles according to two perceptual qualities - concrete learning and abstract learning.

\section{Concrete Learning}

This occurs when learners register information using the five senses while dealing with tangible objects with no hidden meaning.

\section{Abstract Learning}

This refers to visualization, conceptualization, relating to the unseen, using intuition and imagination, and looking for more subtle implications.

Fraser (1970) explained the concept of mathemagenic activity by describing all such related strategies as classes of 'orienting directions'. He defined an orienting direction as a verbal stimulus which disposes the reader to certain aspects of texts. The cognitive theorists are of the opinion that man chooses how he reacts to external and 
internal stimuli. Man, according to them, is an actor of his words. He has the potential to be fully awarded of all his sensations, thoughts, emotions, and perceptions. It is important to find out how people conceptualize or organize what they have learned. Rothkopf (1970) argued that a horse can be led to a river or brook but that the water that gets into his stomach is what he drinks. A teacher is even in a position that he cannot cause learning or perceive it happening directly, unlike horse minders who can at least see and hear whether a horse drinks and how much he drinks. Learners, according to Rothkopf, have autonomous power of his sensations, thoughts, emotions, and perceptions toward the external stimuli. Hence, a student's role or action in the learning process is a direct function of his/her academic achievement in any desired goal.

Orimogunje (2011) recommended a learner's model which can be applied to all subject areas. This model elucidates the state and internal operations of the learner's memory in order to influence meaningful outcomes or responses. The model is represented in Table 1.

Table 1: Model of Learner's Action

\begin{tabular}{|l|l|l|}
\hline \multicolumn{1}{|c|}{$\mathbf{S} \rightarrow$} & \multicolumn{1}{|c|}{$\mathbf{O} \rightarrow$} & \multicolumn{1}{|c|}{$\mathbf{R}$} \\
\hline Overt-mathemagenic activities: & Covert-mathemagenic activities; i.e & Post-treatment: \\
- Reading & subsumptive process: & - Action/decision-taking \\
- Note-taking & -Reorganization of existing structure & - Achievement scores \\
- Instructional objectives & - Recognition of new facts & \\
- Adjunct question & - Collation & \\
$\quad+$ & - Integration & \\
Leaning Materials: & - Interpretation & \\
- Chemistry texts & - Transformation & \\
- Chemistry Practical manual & & \\
- Volumetric & & \\
Apparatus/Reagents & & \\
\hline
\end{tabular}

Note: $\mathrm{O}$ - Internal operation of the learner; $\mathrm{S}$ - Stimulus; $\mathrm{R}$ - Response

The emphasis, therefore, is that to learn from written texts, all statements that the learner must master are translated into interrelated abstract concepts before effective learning could take place. The learning bearing mathemagenic activities of instructional objectives and adjunct questions are therefore placed within the theory of effective processing of word symbols.

According to Cronbach (1977), instructional objectives serve to increase the learner's alertness and focus his attention on the main message of the text. Adjunct questions prompt a greater cognitive engagement with the text. Cognitive formation tends to concentrate on know-how, but the mathemagenic activity stresses the likelihood of execution as well. Erickson and Simon (1980) were of the opinion that mastering learning activities is necessary but not a sufficient condition for their execution.

From Table 1, let us consider two mathemagenic activities that influence the learning of volumetric concept in chemistry.

\section{Texts and Instructional Objectives}

\section{Mode of Instruction}

- $\quad$ Text reading and instructional objectives

- $\quad$ Student-initiated questions and answers

Objective: Students uses the instructional objectives in studying the texts.

Materials: Chemistry textbook, practical manual, practical notebooks, a chart of periodic table, volumetric apparatus and reagents. 


\section{Procedure: Teacher's Activities}

- $\quad$ Teacher introduces the topic with the specific aspects of Mass/Volume relationship in volumetric analysis.

- $\quad$ He instructs students to study the objectives carefully for 5 to 8 minutes.

- He then instructs them to very carefully read, from the text, the uses and application of volumetric apparatus/reagents.

- $\quad$ The teacher asks for words, terms or concepts that are not properly understood.

- $\quad$ The teacher re-describes the conception in light of students' expressions or actions.

- $\quad$ The teacher instructs the students to re-read the text and clamp the clean burette firmly and vertically on a retort stand.

- The teacher asks questions to detect whether the expected objectives have been achieved in the acid/base titration.

- $\quad$ The teacher collects students' practical notebooks for assessment and feedback.

- The teacher adapts task goals in light of the students' descriptions or actions.

\section{Procedure: Students'Activities}

- $\quad$ Students study the assigned text, especially those apparatus/reagents that were used during volumetric analysis.

- $\quad$ Students ask questions.

- $\quad$ Students attempt to clamp the burette in vertical position as instructed by the teacher.

- $\quad$ Students observe the point of neutralization or colour change inside the conical flask, record the reading level of solution inside the pipette or burette, and discuss the difficult activities with their teacher.

\section{Texts and Adjunct Questions}

\section{Mode of Instruction}

- $\quad$ Text reading and adjunct questions

- $\quad$ Student-initiated questions and answers

Objective: Students use adjunct questions in study texts.

Materials: Chemistry textbook, practical manual, practical notebook, a chart of periodic table, volumetric apparatus and reagents

\section{Procedure: Teacher's Activities}

- The teacher introduces the topic with specific aspects of mass/volume relationship in volumetric analysis.

- $\quad$ He instructs the students to read through the text and ask question where necessary.

- $\quad \mathrm{He}$ asks for any words or terms that are not properly understood or for any other clarifications.

- The teacher instructs the students to re-read the text and answer questions in light of the teacher's description of the concept.

- $\quad$ The teacher instructs the students to clamp the clean burette firmly and vertically on the retort stand.

- The teacher asks questions to detect whether the expected objectives have been achieved in the acid/base titration.

- $\quad$ The teacher collects students' practical notebooks for assessment and feedback.

- The teacher adapts tasks good in light of the students' descriptions/actions. 


\section{Students'Activities}

- $\quad$ Students read the assigned texts.

- $\quad$ Students ask questions in light of the teacher's description.

- $\quad$ Students attempt to clamp the burette in vertical position as described by the teacher.

- $\quad$ Students observe and record results and discuss difficult activities with their teacher.

- $\quad$ Students modify actions in light of feedback.

- Students adapt actions in light of the teacher's conception.

According to Laurillard (1996), a teaching strategy should take into consideration the fact that the learning process is a dialogue between teacher and student and having the following characteristics:

Discursive

Conceptions of the discourse brought by both teacher and learner should be accessible to the other. They must agree on learning goals and task goals, while the teacher provides an environment within which students can act on, generate, and receive feedback on descriptions appropriate to the topic goal.

Adoptive

To determine the continuing dialogue, teachers need to understand the relationship between their own goal and the students' conceptions.

Interactive

Students need to act and achieve the task goal, while the teacher needs to provide meaningful feedback on the actions that relate to the nature of the task.

Reflective

Teachers need to support the process which allows students to reflect on the feedback of their actions to the topic goal. Reflection helps to establish a link between the goal action-to-feedback part of teaching.

\section{CONCLUSION}

The study of mathemagenic activities focuses on the effective use of orienting stimuli or external conditions that might occur to give the internal processing necessary information for learning to take place. It is believed that when textual materials are presented with useful pedagogical aids, such as instructional objectives, adjunct in text and reading habit in text, it offers the students self-reliance in solving chemical problems. It also facilitates the students' independent study, as well as enhances the teacher's instructions in the classroom situation, resulting in greater involvement of students during the chemistry lesson. Perhaps, the beneficial effect of mathemagenic activities could be applied to all subject areas.

\section{RECOMMENDATIONS}

- Chemistry teachers need to enhance the instructional process by deliberately incorporating the use of mathemagenic activities, such as reading, note taking, recording of observation, instructional objectives and adjunct questions, into the teaching process. However, since virtually none of the books currently in use possess these aids, it would be innovative for teachers to try to construct their own for use in the classroom.

- $\quad$ Authors should provide for learners' materials that are not only relevant but also instructionally useful for the attainment of the overall objectives of the subject. These texts should carry as many of these useful pedagogical aids as can be reasonably integrated into the body of information being presented to students. Preface to texts should carry instructions on how to use these aids for maximum effects. 
- $\quad$ The selection of recommended textual materials needs to be done more prudently as teachers often wonder what criteria are employed in selecting certain textual materials for student use. Professional consideration of features, such as scope and relevant of contents, use of text accessories, and level of readability, as well as character of presentation, should be evident in the selection process. In countries where competition is high and quality is adequately emphasized, accessories constitute important measures of potential effectiveness in textual evaluation.

\section{IMPLICATIONS}

- This study shows how mathemagenic activities could be used to minimize some problems and increase the probability of students' improvement in the instructional process, especially during the chemistry lesson. That is, it makes the students transform the instructive information into internal representation.

- Mathemagenic activity encourages good learning habits, pinpoints areas of confusion and eliminates students' misconceptions about the scientific principle and procedure in some concepts of Chemistry. It makes the teacher be open and flexible to accommodate students' views through the use of some mathemagenic activities as orienting stimuli. This study has developed an appropriate learning activity that would influence students' learning in cognitive, affective, and psychomotor levels of teaching outcomes.

\section{AUTHOR INFORMATION}

Dr. Tunde Orimogunje was born at Ijare in Ifedore local Government Area of Ondo State, Nigeria. He attended Oyemekun Grammar School Akure for His Secondary Education between 1975 and 1980. He obtained his first degree in Chemistry education in Second Class Upper Division and afterward proceeded to the University of AdoEkiti, Ekiti State, Nigeria where he obtained His M.Ed and Ph.D. degrees in Science Education. He has published many articles, especially on the teaching and learning of Chemical concepts in journals within and outside Nigeria. $\mathrm{He}$ is a member of Science Teachers' Association of Nigeria and is currently the coordinator for the pre-degree programme in Science Education in Adekunle Ajasin University Akungba Akoko, Nigeria. Dr. Orimogunje is married to Funmibi and the union is blessed with four children. E-mail: tunderorimogunje@yahoo.com

\section{REFERENCES}

1. Ausubel, D.P. (1963): The psychology of meaningful learning. New York: Grune and Station.

2. Ausubel, D. P. (1980): The use of advance organizer in the learning retention of meaningful verbal learning: Journal of Education Psychology. 51-58

3. Balogun, T. A. (1976): A study in mathemagenic: An investigation of a topography of learning control in a science subject. Unpublished Ph.D. Thesis, Teachers' College, Columbia

4. Draper, S. (2000): Applying what we know: student learning styles: London: The Reader' s Digest Association Limited.

5. Efimova, E. (2005): Discovering the iceberg of knowledge work: a web log case: http/blog.MAthemagenic.com/2004/02/29 html

6. Egbugara. U.O. (1983): Effects of orienting stimuli on the attitudes and achievement in Biology of group of Nigeria Secondary Schools pupils. Unpublished Ph. D. Thesis, University of Ibadan.

7. Rickson, K.A. and Simon, H.A (1980): Verbal reports as data. Psychological Review 87, 215-251

8. Frazer, L.T. (1970): Boundary Conditions of mathemagenic behaviour. Review of Educational Research, 40 (3). 17-22

9. Ibegbulam, C. M. (1980): Effect of orienting stimuli on the attitude and achievement in Biology of a group of Nigeria Secondary School pupils. Unpublished Ph.D. Thesis, University of Ibadan.

10. Jonassen, D. H. (1988): Generative learning vs mathemagenic control of text processing. Hillsdale, N. J. Eribaum

11. Laurillard, D. (1993): Rethinking University Teaching: A frame work for the effective use of Educational Technology. Routledge: London 283-286.

12. Laurillard, D. (1996): The changing University: Conversational frame work Routledge: London, 27-30.

13. Lawson, A. E. (1982): Formal Reasoning Achievement and Intelligence, Science Education, 66(1), 77-83. 
14. Nwankpa, N. O. (1981): Learning and retention in Biology. A test of Ausubelian subject matter. Ph.D. Thesis University of Ife, Ile-Ife.

15. Orimogunje, T. (2011): Effect of mathemagenic activities on Students' learning outcomes in Senior Secondary School Chemistry. Unpublished Ph.D. Thesis, University of Ado-Ekiti Ekiti State.

16. Piaget, J.(1958): The language and thought of the child. London: Routledge and Kegan Paul. 1-49.

17. Rothkopf, E. T. (1963): Some conjectures about inspection behaviour in learning from written sentences and the response made problem in programmed self-instruction. Journal of Programmed instruction, 2, 3146.

18. Rothkopf (1996): Control of mathemagenic activities. In D.H. Jonassen, (Ed.), Handbook for research on Educational Communication and Technology, New York: McMillan.

19. Rothkopf, E.T. (2009): An immodest proposal: Pedagogic Information supports for teachers; Department of human Development, Teachers College, Columbia University, New York.

20. Sa'adah, M. and Sion, H.L. (2003): What learning means: A Cognitive Pathway in learning chemistry. Institute of Education. University of London.

21. West African Examination Council (May/June, 2009). General Certificate of Education ('O' Level) Chief Examiner's Reports, Nigeria Lagos: WAEC. 
NOTES 